\title{
Optical Properties of Copper-Zinc Sulphide Network from Mixed Single Solid Source Precursors of Copper and Zinc Dithiocarbamates
}

\author{
Joseph Onyeka EMEGHA ${ }^{1, *}$, Chukwudi Mcdonald OKAFOR ${ }^{2}$ and \\ Kingsley Eghonghon UKHUREBOR ${ }^{3}$
}

\author{
${ }^{I}$ Department of Physics, University of Benin, Benin City, Edo State, Nigeria \\ ${ }^{2}$ Department of Physics Education, Federal College of Education (Technical) Asaba, Delta State, Nigeria \\ ${ }^{3}$ Department of Physics, Edo State University Uzairue, Edo State, Nigeria
}

('Corresponding author's e-mail: jjjemegha@yahoo.com)

Received: 18 February 2020, Revised: 28 April 2020, Accepted: 8 May 2020

\begin{abstract}
Thin films of copper-zinc sulphide (CxZn1-xS) have been deposited by metal-organic chemical vapour deposition (MOCVD) technique at $400{ }^{\circ} \mathrm{C}$ on soda-lime substrates. The films contained copper dithiocarbamate and zinc dithiocarbamate of various concentrations. The effect of the precursor's concentration was investigated using Fourier transforms infrared (FTIR) spectroscopy and UV-Vis Spectrophotometer. The precursors' FTIR spectrums have the characteristics of copper sulphide and zinc sulphide absorption bands below $800 \mathrm{~cm}^{-1}$. The optical properties for all the samples were studied by reading the absorbance and transmittance spectra in the range of $300-900 \mathrm{~nm}$. The results indicate direct bandgap energy that ranged between 2.20 to $3.42 \mathrm{eV}$. The films were found to have a very high transmittance in the visible and near-infrared regions and an average reflectance of about 0.14 in the same regions. Optical constants like refractive index, extinction coefficient, and optical conductivity were estimated as a function of photon energy. The various properties exhibited by the films indicate that the films can find application in various optoelectronic devices.
\end{abstract}

Keywords: Dithiocarbamate, Precursors, Metal-organic chemical vapour deposition (MOCVD), Thin films, Fourier transforms infrared (FTIR), Spectrophotometer, Copper, Zinc

\section{Introduction}

Metal-organic chemical vapour deposition (MOCVD) is a special form of chemical vapour deposition (CVD) technique that uses metal-organic compounds as source material for thin-film growth [1]. It is an improvement over other chemical deposition routes. Metal organics have been used to cover an element attached to one or more carbon atoms of a hydrocarbon group [2]. Since first reported in 1960, the technique has been used as one of the methods for epitaxial growth of compound semiconductors for both research and commercial interest. As organic molecular architecture knowledge improves, MOCVD seems to offer a possible solution to many problems in metal extraction and purification, surface coatings, and chemical synthesis [1]. The attraction of MOCVD is in its adaptability to large area deposition, highquality films, cost-effectiveness, simple apparatus, uniform coverage of the substrate, low-temperature deposition, and growth under high gaseous partial pressure [3,4]. A fundamental part of tailoring properties of the material in the MOCVD technique lies in the proper choice of the molecular precursors, whose design greatly affects the nature and properties of the final product [5]. Developing precursors with a set of physical properties such as high purity, economical, easy preparation route, non-toxicity, high volatility, and thermal stability, and good thermal decomposition is necessary for high-quality thin films with minimized health hazards and environmental issues [2,6] 
However, the conventional CVD precursors have many drawbacks such as difficulty controlling stoichiometry, incorporation of impurities, unwanted side reactions, and high processing temperature, which may cause diffusion of layers. To overcome these limitations, the development of alternative single solid source precursors has been pursued. The use of a single source precursor has potential advantages over conventional precursors. First of all, it provides the unique advantages of mildness, safety, simplified fabrication procedure, simplified equipment, and delivers exact control over stoichiometry of the films $[5,7]$. One more attraction of this technique is seen in the metastable phase formation of the resultant products, which are sometimes not possible using the conventional deposition methods. For this reason, copper-zinc sulphide $\left(\mathrm{Cu}_{\mathrm{x}} \mathrm{Zn}_{1-\mathrm{x}} \mathrm{S}\right)$ thin films were synthesized at $400{ }^{\circ} \mathrm{C}$ using mixed single solid source precursors of copper and zinc dithiocarbamates. The material was chosen because it has good optical and electrical properties and is less toxic when compared to other ternary materials like copper-zinc telluride $\left(\mathrm{CuZnTe}_{2}\right)$, copper-zinc selenide $\left(\mathrm{CuZnSe}_{2}\right)$, and copper aluminum selenide $\left(\mathrm{CuAlSe}_{2}\right)$. Besides the typical Uv-Vis absorption measurements, the Fourier transform infrared (FTIR) spectroscopy approach was employed to investigate the precursors and films' chemical compositions, which is necessary for determining the molecular state of the materials.

\section{Materials and methods}

$\mathrm{Cu}_{\mathrm{x}} \mathrm{Zn}_{1-\mathrm{x}} \mathrm{S}$ thin films were deposited onto clean soda-lime (glass) substrates by MOCVD technique using a mixture of copper dithiocarbamate and zinc dithiocarbamate precursors. Soda-lime substrates were used in this study because its chemical components do not interfere with the properties of copper zinc sulphide thin films. The precursors preparation and deposition process have been reported elsewhere [8]. The mixture was pulverized into powders and deposited at $400{ }^{\circ} \mathrm{C}$ for $2 \mathrm{~h}$ using nitrogen as the carrier gas. Before the deposition, the soda-lime substrates were washed with detergent and rinsed in distilled water, acetone, methanol and distilled water respectively. Four samples of $\mathrm{Cu}_{\mathrm{x}} \mathrm{Zn}_{1-\mathrm{x}} \mathrm{S}$ thin films with various concentrations $(\mathrm{x}=0.9,0.7,0.3$ and 0.1$)$ were produced and labeled as C1, C2, C3 and C4 as shown in Table 1.

Table 1 Percentage combination of the various samples.

\begin{tabular}{lcc}
\hline Samples & molecular Precursors & Deposition Temperature $\left({ }^{\circ} \mathbf{C}\right)$ \\
\hline C1 & $90 \%$ copper dithiocarbamate $+10 \%$ zinc dithiocarbamate & 400 \\
C2 & $70 \%$ copper dithiocarbamate $+30 \%$ zinc dithiocarbamate & 400 \\
C3 & $30 \%$ copper dithiocarbamate $+70 \%$ zinc dithiocarbamate & 400 \\
C4 & $10 \%$ copper dithiocarbamate $+90 \%$ zinc dithiocarbamate & 400 \\
\hline
\end{tabular}

The infrared spectroscopy of the films and precursors were carried out using a Shimadzu 8400 FTIR spectroscopy. The elemental thicknesses (44.5, 57.6, 52.3, and $25.9 \mathrm{~nm}$ ) were determined using Rutherford backscattering spectroscopy (RBS). The optical characterization of the samples was done using Double Beam Shimadzu-UV-1800 scanning spectrophotometer. The absorbance and transmittance of the films were measured in the wavelength range of 300 to $900 \mathrm{~nm}$ in a step size of 20. Prior to the reading, a clean soda-lime substrate was used as a reference. Other optical properties were estimated using the following relations below.

The transmittance $(\mathrm{T})$ and absorbance $(\mathrm{A})$ of semiconducting materials are generally derived from the expression [9];

$\mathrm{T}=10^{-A}$ 
And, refractive index (n) is estimated using the computational method of the corrected reflectance (R) data expressed as;

$\mathrm{n}=\frac{-(R+1) \pm \sqrt{3 R^{2}+10 R-3}}{2(R-1)}$

The extinction coefficient $(\mathrm{k})$ and optical conductivity $(\sigma)$ are obtained using the equations [10];

$\mathrm{k}=\frac{(\alpha \lambda)}{(4 \pi)}$

$\sigma=\frac{(\alpha n c)}{(4 \pi)}$

where $\alpha$ is the absorption coefficient, $\lambda$ is the wavelength and $\mathrm{c}$ is the speed of light. As a direct band gap semiconducting material, the absorption coefficient $(\alpha)$ is related to photon energy $(\mathrm{eV})$ as follows [7];

$\alpha=\frac{Z(h v-\mathrm{Eg})^{0.5}}{h v}$

Here, $\mathrm{z}$ is a constant, $h$ is Planck's constants, $v$ is the frequency of incident photon and $\mathrm{E}_{\mathrm{g}}$ is the optical band gap of the material.

\section{Results and discussion}

A typical infrared spectrum of copper dithiocarbamate precursor is presented in Figure 1. Careful observation showed that the $\mathrm{Cu}-\mathrm{S}$ bond was below $869.92 \mathrm{~cm}^{-1}$. Also, a very strong and dominating band belonging to the $\mathrm{O}-\mathrm{H}$ group was observed with two peaks at 3421.83 and $3142.15 \mathrm{~cm}^{-1}$ attributed to O-H and N-H stretching vibrations respectively. The existence of a broad $\mathrm{OH}$ group band with 2 peaks is due to the presence of amino salt in the spectrum. The bands formed at 2486.33 and $2407.24 \mathrm{~cm}^{-1}$ are due to the weak C-H stretching vibrations. The weak triple C-C bond is responsible for the vibrations at 2266.43, 2054.26 and $1861.37 \mathrm{~cm}^{-1}$. The band at $1637.62 \mathrm{~cm}^{-1}$ is due to $\mathrm{C}=\mathrm{O}$ stretching modes of vibration. Bonding at $1560.46,1498.76$ and $1400.37 \mathrm{~cm}^{-1}$ correspond to the $\mathrm{C}-\mathrm{H}$ stretching vibrations. The spectrum also showed a C-O vibration in the 1250 to $1000 \mathrm{~cm}^{-1}$ region with a doublet peak at $1103.32 \mathrm{~cm}^{-1}$ which may be assigned to the $\mathrm{C}-\mathrm{H}$ stretching. The formation of the doublet is due to Fermi resonance [11].

The infrared spectrum of zinc dithiocarbamate precursor, as well as the expected absorption frequency band is illustrated in Figure 2. The figure shows that the $\mathrm{Zn}-\mathrm{S}$ bonding was within 800 to 400 $\mathrm{cm}^{-1}$. Similar observations have been reported in literature [11,12]. Conspicuously seen is the broad band associated with the $\mathrm{O}-\mathrm{H}$ group at $3446.91 \mathrm{~cm}^{-1}$ and N-H peak at $3126.71 \mathrm{~cm}^{-1}$. Other prominent bands in the spectrum include C-H stretching vibrations at 2966.60 and $2852.81 \mathrm{~cm}^{-1}$. The region between 2500 to $1750 \mathrm{~cm}^{-1}$ consisted of weak sharp combinations and overtone bands which may be the result of the polar bonds within the $\mathrm{C} \equiv \mathrm{C}$ vibration. $\mathrm{C}=\mathrm{O}$ stretching mode was observed at $1491.02 \mathrm{~cm}^{-1}$. Bands formed at 1433.16, 1265.36 and $1242.20 \mathrm{~cm}^{-1}$ are attributed to $\mathrm{C}-\mathrm{H}$ bending vibrations. The bands at 1114.89 , 1026.16 and $997.23 \mathrm{~cm}^{-1}$ are due to $\mathrm{C}-\mathrm{C}$ vibrations. These peaks parallel well with those of other dithiocarbamate in literature.

Figure 3 shows the spectrum of the deposited $\mathrm{Cu}_{\mathrm{x}} \mathrm{Zn}_{1-\mathrm{x}} \mathrm{S}$ films (Sample C1). The other samples are similar. The figure showed that the films had no evidence of the organic radicals present in the dithiocarbamate precursors, an indication of a complete decomposition of the precursors to form copper zinc sulphide thin films [14]. A phenomenon that is consistent with metal-metal chalcogenides. 
由SHIMADZU

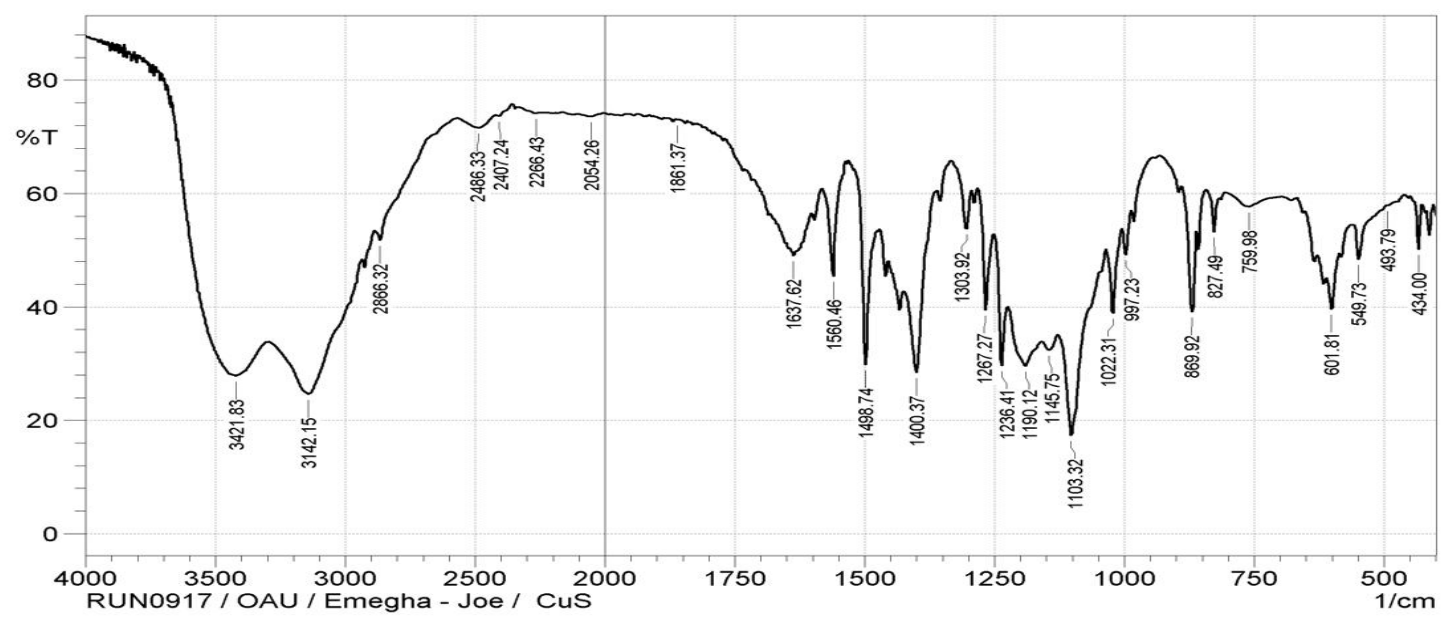

Figure 1 Infrared spectrum of copper dithiocarbamate precursor.

Ф SHIMADZU

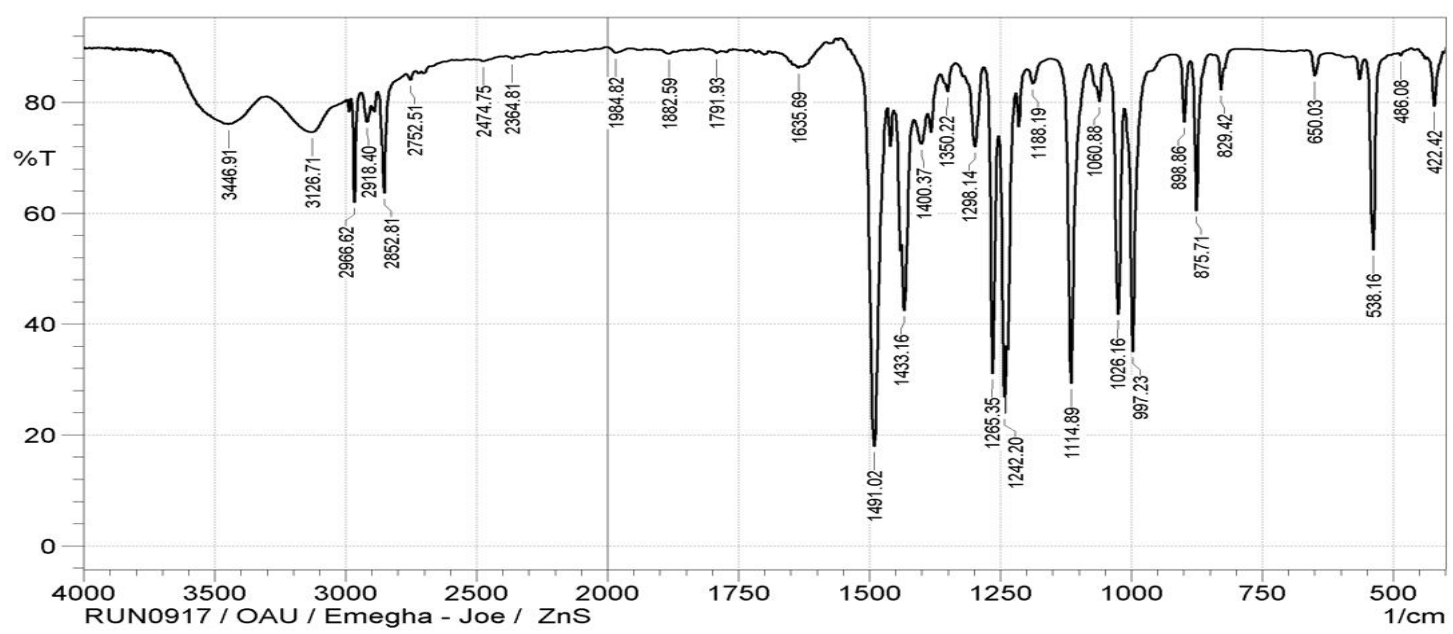

Figure 2 Infrared spectrum of zinc dithiocarbamate precursor. 


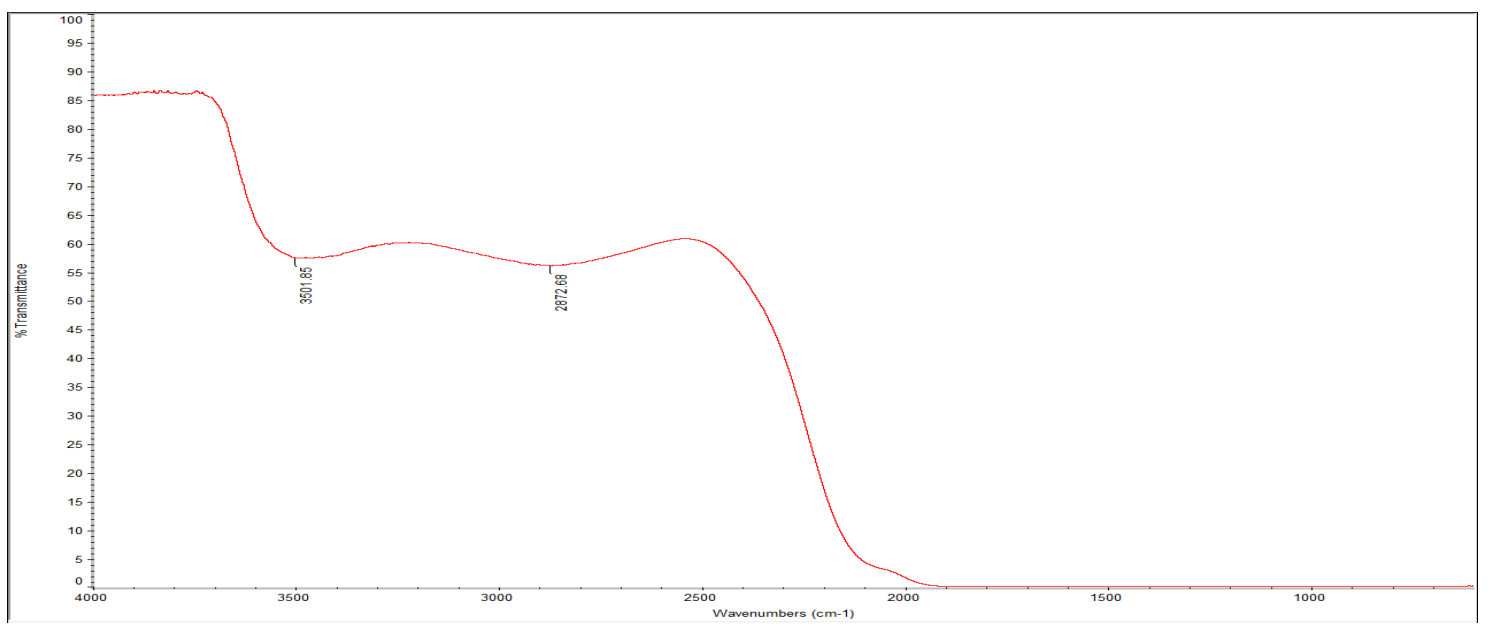

Figure 3 Infrared spectrum of $\mathrm{Cu}_{\mathrm{x}} \mathrm{Zn}_{1-\mathrm{x}} \mathrm{S}$ Films on soda-lime glass (Sample C1).

Figure 4 shows the plot of the optical transmittance against wavelength. It was observed that the films had a very high transmittance of above $75 \%$ in the visible and near infrared regions. Sample C4 had the least transmittance in the infrared region, while Sample C2 had the highest in same region. Also, copper concentrations were found to decrease with transmittance. The decrease in transmittance with copper concentration may be attributed to the formation of copper doped zinc sulphide nano-crystals. As the film nano-crystals are increasing, the transparency is also increasing. Therefore, the reduction of copper concentrations makes the films more transparent.

This observation agrees well with Ezenwa and Okoli [15] who reported a transmittance of above 80 $\%$ in the visible and infrared regions. A somewhat lower transmittance was reported by Uhuegbu et al. [10] using solution growth technique. The high transmittance in this study is due to the crystallinity of the films, which in turn reduces the defects in the grain boundaries and increases the transmittance [16]. Films of such high transmittance could serve as transparent conducting materials in light emitting devices.

Figure 5 shows the relationship between the optical absorbance of the films and wavelength. In all the samples, it was observed that the absorption were high in the ultraviolet region of the spectra. Also from the figure, the absorbance decreases with copper concentration. Such a decrease in absorbance may be due to structural defects such as surface irregularity and defect density in the $\mathrm{Cu}_{\mathrm{x}} \mathrm{Zn}_{1-\mathrm{x}} \mathrm{S}$ network as a result of copper incorporation. The absorbance values were seen to decrease throughout the visible and near infrared regions. Figure 6 shows the reflectance as a function of the wavelength of the deposited $\mathrm{Cu}_{\mathrm{x}} \mathrm{Zn}_{1-\mathrm{x}} \mathrm{S}$ thin films. We note that the reflectance decreases with wavelength for all samples and, also, with concentration. Generally, all the samples have low reflectance values that lie between 6 to $20 \%$. However, at a wavelength greater than $700 \mathrm{~nm}$, sample $\mathrm{C} 1$ has the highest value, which may result from the density of the film decreasing with copper concentrations. This low value of the estimated reflectance is according to Uhuegbu et al. [10] and Ezenwa and Okoli [15] for copper zinc sulphide thin films. The low reflective properties of the samples make the films good material for anti-reflective coatings [17]. 


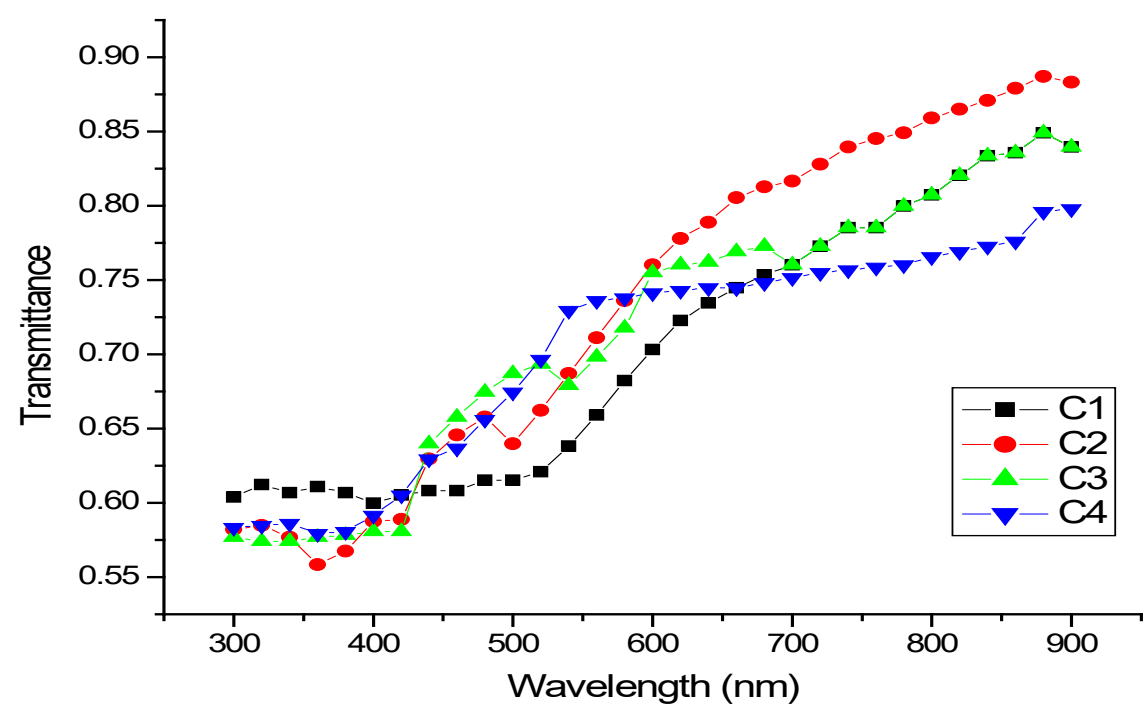

Figure 4 Transmittance spectrum of $\mathrm{Cu}_{\mathrm{x}} \mathrm{Zn}_{1-\mathrm{x}} \mathrm{S}$ thin films.

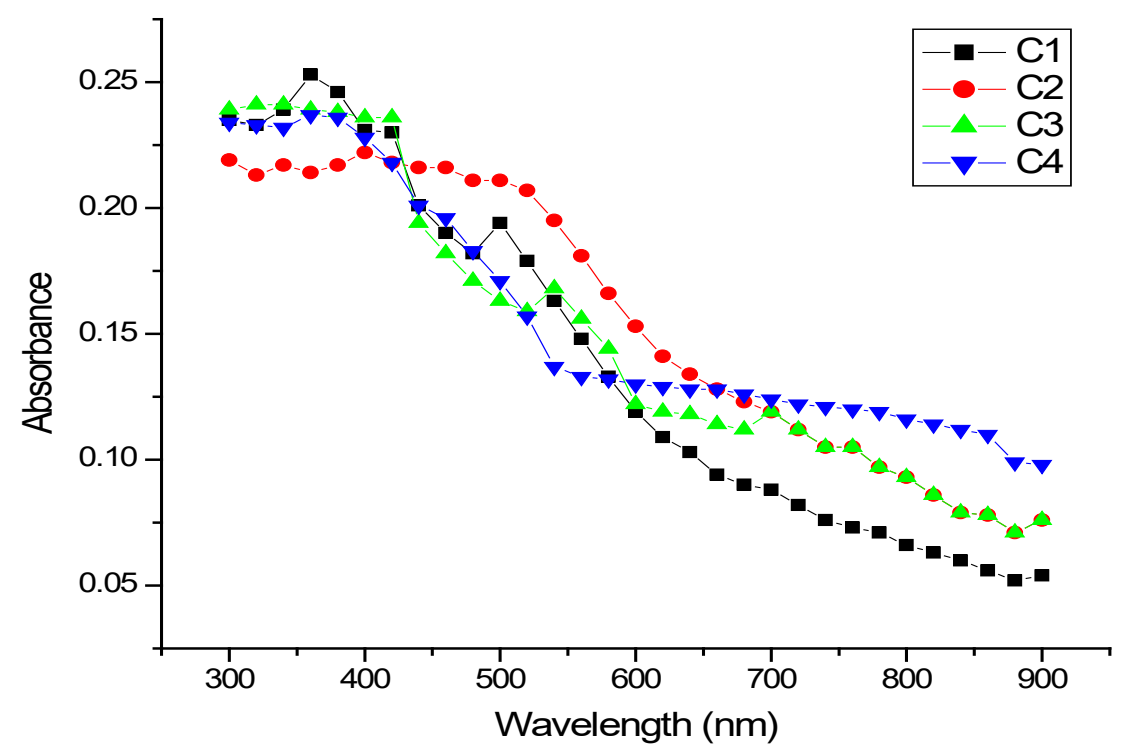

Figure 5 Absorbance spectrum of $\mathrm{Cu}_{\mathrm{x}} \mathrm{Zn}_{1-\mathrm{x}} \mathrm{S}$ thin films. 


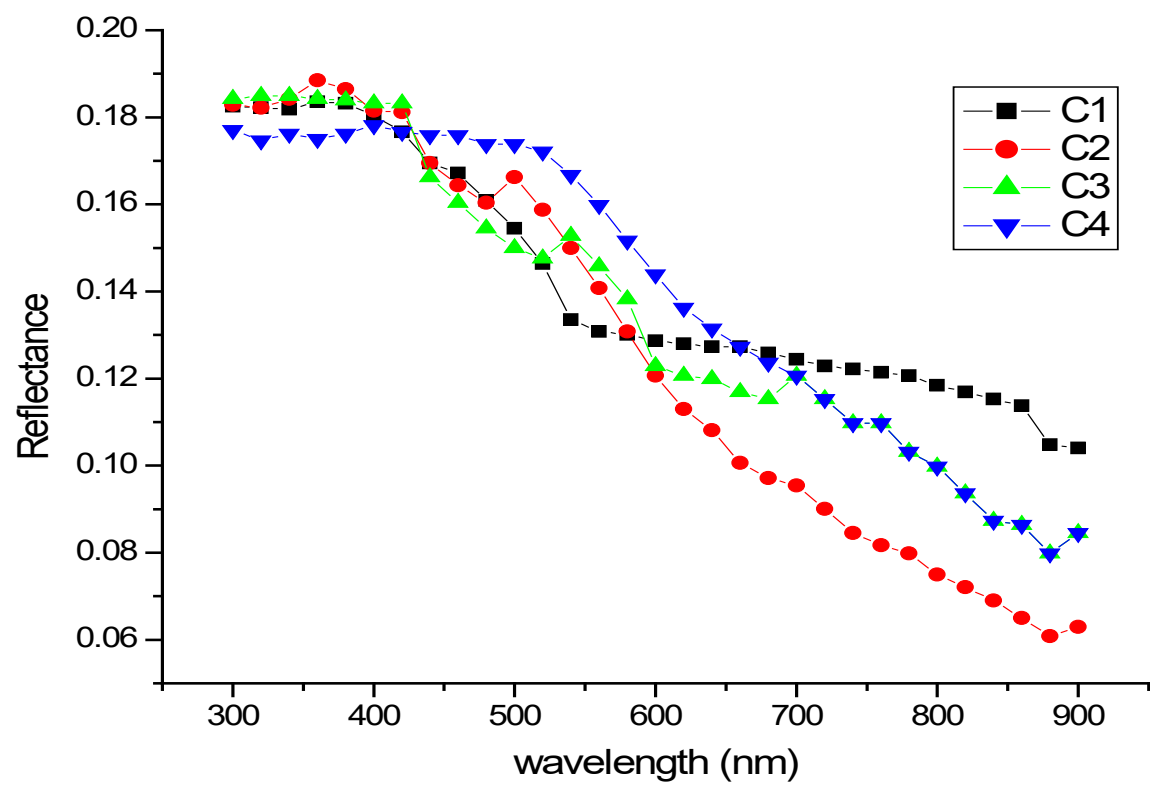

Figure 6 Reflectance spectrum of $\mathrm{Cu}_{\mathrm{x}} \mathrm{Zn}_{1-\mathrm{x}} \mathrm{S}$ thin films.

The optical band gap (Eg) of the deposited films was estimated from Eq. (5) by plotting $(\propto \mathrm{hv}) 2$ against photon energy (hv), and the values were found to be between 2.20 to $3.42 \mathrm{eV}$ [8]. The direct bandgap energy increases with an increase in zinc concentration for all compositions, as depicted in Table 2. This result is due to the ability of zinc to replace copper atoms in $\mathrm{Cu}_{\mathrm{x}} \mathrm{Zn}_{1-\mathrm{x}} \mathrm{S}$ network. The estimated bandgap (Eg) values are consistent with those of $\mathrm{CuS}$ and $\mathrm{ZnS}$, where each of them has been known as a direct bandgap semiconductor with compositional modulation ability. These observations are in good agreement with the works of Sreejith et al. [18] and Noriyuki et al. [19] for copper zinc sulphide thin films. They attributed the increased bandgap to the direct effects of enlarged grain sizes as well as a reduction in structural defect within the films. The observed trend may also be connected to secondary phases in small quantities that may not be detected within the films [20]. Furthermore, the increased direct bandgap due to a decrease in copper incorporation makes the films suitable for optoelectronic devices. The material will allow more short-wavelength photons to reach the absorber layer and generate more photocurrent than copper sulphide thin films [21].

The refractive index (n) against photon energy is indicated in Figure 7. From the graph, it was found that the refractive index increases with photon energy for all the samples. Sample C1 has the highest (average) refractive index of approximately 1.95 in the high-energy region. However, as the copper concentration is decreased, the average refractive indexes were found to fall and rise within the range of 1.95 and 1.82 (Table 2). This trend in the refractive index was possibly due to the trapped photon energy within the samples' grain boundaries [22].

The dependence of the extinction coefficients $(\mathrm{k})$ with photon energy for the various samples is illustrated in Figure 8. It was found that the extinction coefficient increases with photon energy and decreases with copper concentration. Table 2 shows the average extinction coefficients of the samples at various copper concentrations. Overall, the films exhibited low extinction coefficients over the energy range, losing very low absorption energy along the wavelength regions [23]. Figure 9 shows the optical conductivity spectra of the samples and the photon energy. It revealed that the conductivity of the films 
increased along the low and high energy regions. From Table 2, it shows a fairly high value of optical conductivities that varies with copper concentrations. The variation in the average values indicates that the films depend largely on the concentration.

Table 2 Summary of some optical properties of $\mathrm{Cu}_{\mathrm{x}} \mathrm{Zn}_{1-\mathrm{x}} \mathrm{S}$ thin films.

\begin{tabular}{lllll}
\hline & \multicolumn{5}{c}{ Samples } \\
\cline { 2 - 5 } Optical properties of $\mathbf{C u}_{\mathbf{x}} \mathbf{Z n}_{\mathbf{1 - x}} \mathbf{S}$ thin films & $\mathbf{C 1}$ & $\mathbf{C 2}$ & $\mathbf{C 3}$ & $\mathbf{C 4}$ \\
\hline Optical band gap $(\mathrm{eV})$ & 2.20 & 2.25 & 3.35 & 3.42 \\
Refractive index $(\mathrm{n})$ & 1.95 & 1.82 & 1.88 & 1.83 \\
Extinction coefficient $(\mathrm{k}) \times 10^{-3}$ & 8.5 & 7.3 & 7.9 & 7.4 \\
Optical conductivity $(\sigma) \times 10^{12}$ & 9.4 & 8.2 & 7.9 & 9.3 \\
\hline
\end{tabular}

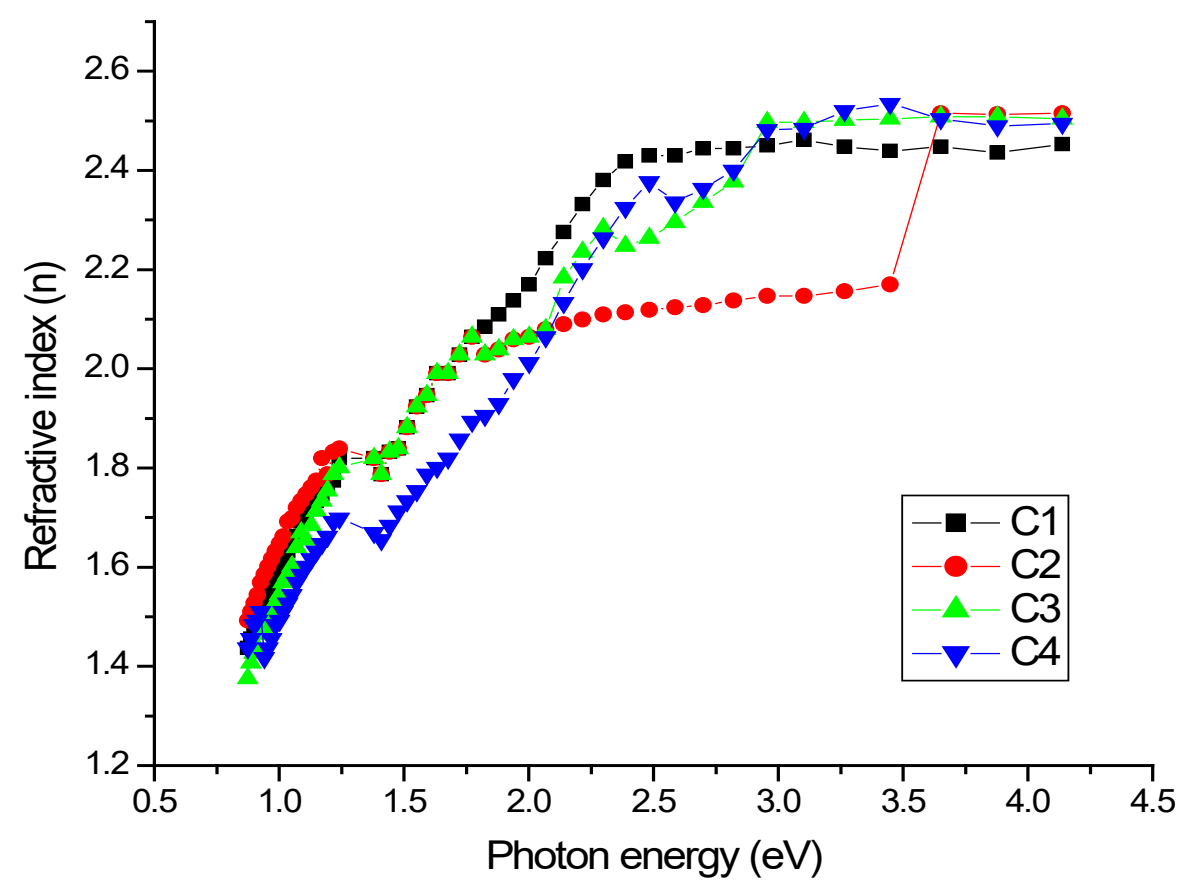

Figure 7 Refractive index against photon energy of $\mathrm{Cu}_{\mathrm{x}} \mathrm{Zn}_{1-\mathrm{x}} \mathrm{S}$ thin films. 


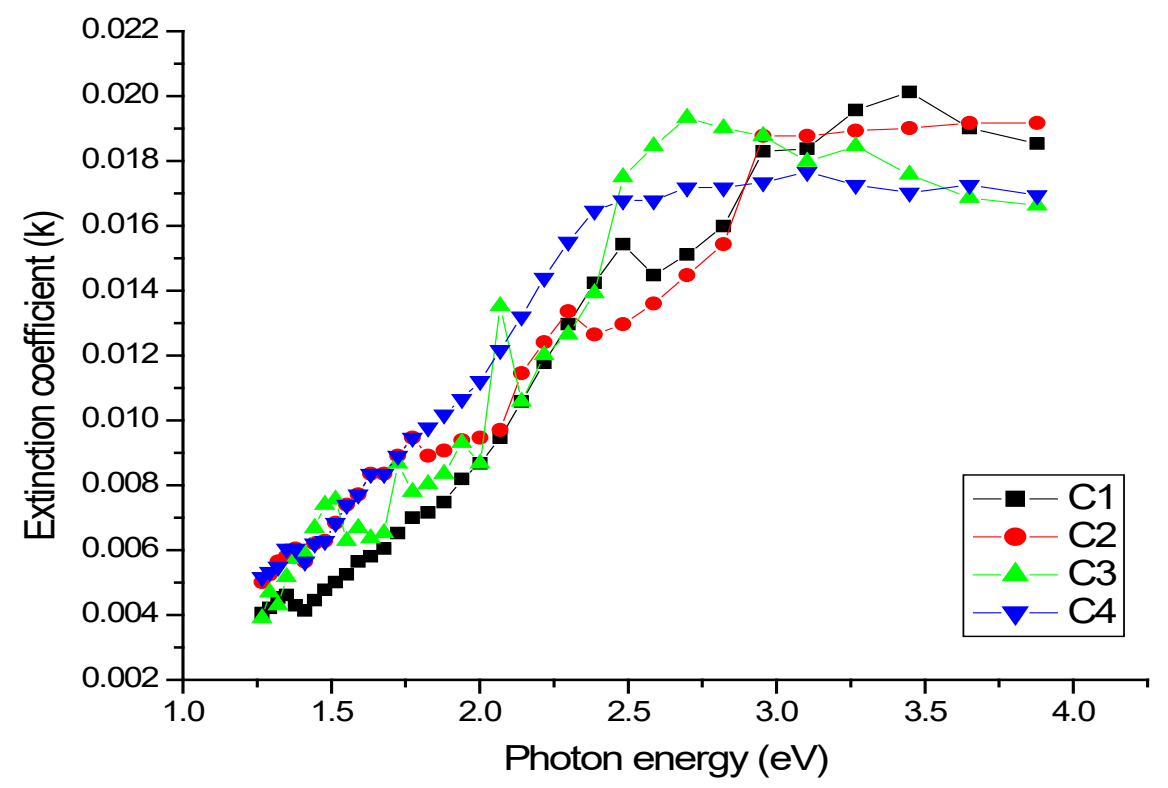

Figure 8 Extinction coefficient against photon energy of $\mathrm{Cu}_{\mathrm{x}} \mathrm{Zn}_{1-\mathrm{x}} \mathrm{S}$ thin films.

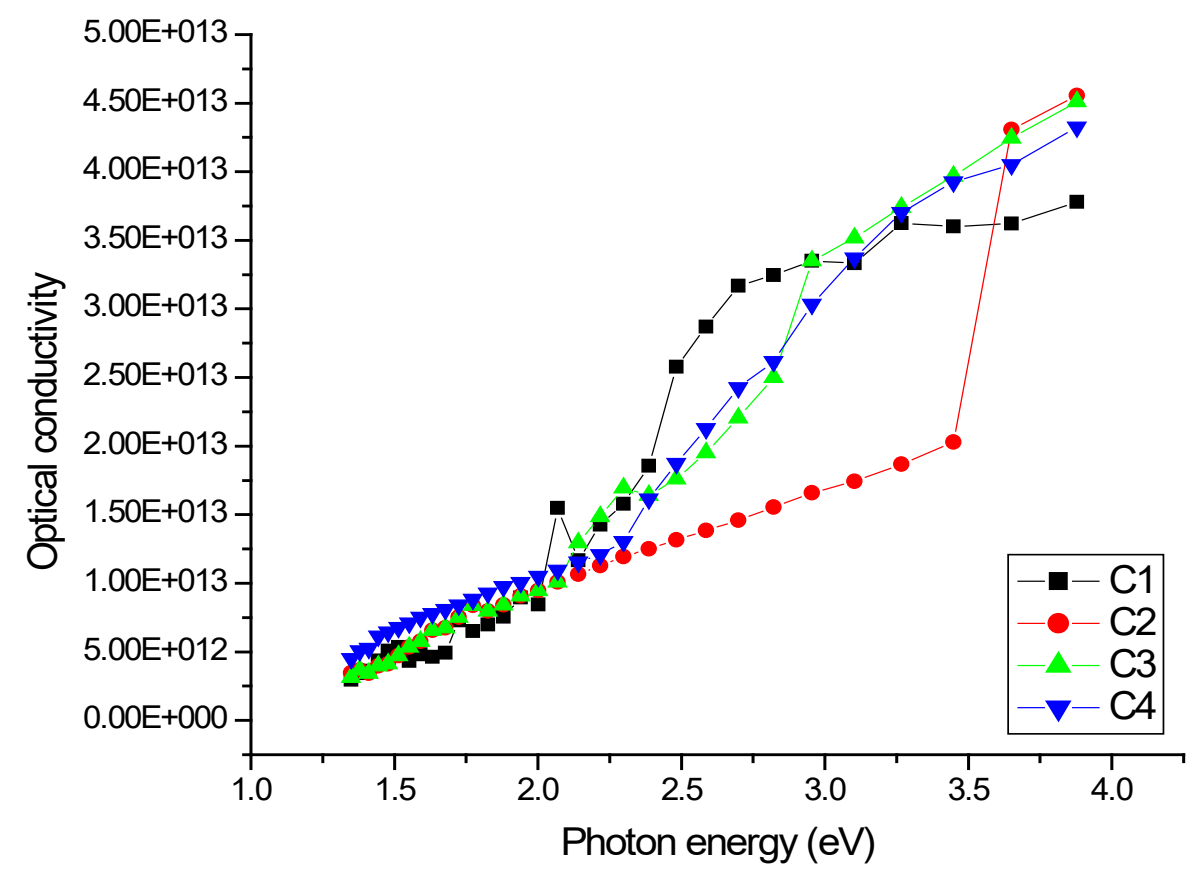

Figure 9 Optical conductivity against photon energy of $\mathrm{Cu}_{\mathrm{x}} \mathrm{Zn}_{1-\mathrm{x}} \mathrm{S}$ thin films. 


\section{Conclusions}

Optical analysis of MOCVD deposited $\mathrm{Cu}_{\mathrm{x}} \mathrm{Zn}_{1-\mathrm{x}} \mathrm{S}$ thin films have been studied. The FTIR analysis showed the deposited film contained copper, zinc, and sulphur. The transmittance spectral increases rapidly with wavelength $(300-900 \mathrm{~nm})$ and decreases with zinc concentrations. The reflectance was generally low with a direct optical band gap that varies from 2.20 to $3.42 \mathrm{eV}$. The refractive index, extinction coefficient, and optical conductivities were also affected by the concentrations. These properties exhibited by the deposited films at different concentrations confirm the films as good material for coatings of different types and other optoelectronic devices.

\section{Acknowledgements}

The authors would like to express profound gratitude to the staff and students of the Solid State and Material Science Group of the Department of Physics and Engineering Physics, Obafemi Awolowo University, Ile-Ife, Nigeria for their guidance and for allowing us to use their MOCVD facilities.

\section{References}

[1] A Khan. 2011, Synthesis of stroutium culprate $\left(\mathrm{ScCu}_{2} \mathrm{O}\right)$ by $\mathrm{MOCVD}$ as a p-type transparent conducting oxide thin films. Ph.D. Dissertation. Grenoble University.

[2] HO Pierson. Handbook of Chemical Vapour Deposition (CVD): Principles, technology and application. William Andrew, New York, 1999.

[3] KO Oyedotun, E Ajenifuja, B Olofinjana, BA Taleatu, E Omotoso, MA Eleruja and EOB Ajayi. Metal-organic chemical vapour deposition of lithium manganese oxide films via single solid source precursors. Mater. Sci. Poland 2015; 33, 725-31.

[4] E Omotoso, GA Adegboyega, MA Eleruja, B Olofinjana, OO Akinwunmi, OO Ilori, A Taleatu and EOB Ajayi. Synthesis and some properties of MOCVD lead sulphide and lead cadmium sulphide thin films. J. Non Oxide Glass. 2013; 5, 9-19.

[5] MA Ehsan. 2014, Fabrication and characterization of nano-structure ceramic thin films from single solid source and mixed molecular precursors. Ph.D. Dissertation. University of Malaysia, Kuala Lumpur, Malaysia.

[6] MA Malik, M Afzaal and P O’Brien. Precursor chemistry for main group elements in semiconducting materials. Chem. Rev. 2010; 110, 4417-46.

[7] JO Emegha, J Damisa, FO Efe, B Olofinjana, M Eleruja and SO Azi. Preparation and characterization on metal organic vapour deposited copper zinc sulphide thin films using single solid source precursors. Eur. J. Mater. Sci. Eng. 2019; 4, 11-22.

[8] JO Emegha, B Olofinjana, MA Eleruja, EF Ochuko and S Azi. Preparation and physical properties $\mathrm{Cu}_{\mathrm{x}} \mathrm{Zn}_{1-\mathrm{x}} \mathrm{S}$ thin films deposited by metal organic chemical vapour deposition technique. J. Mater. Sci. Res. Rev. 2019; 2, 1-9.

[9] JO Emegha, ED Elete, EF Ochuko and AC Adebisi. Optical and electrical properties of semiconducting $\mathrm{ZnS}$ thin films prepared by chemical bath deposition technique. J. Mater. Sci. Res. Rev. 2019; 4, 1-8.

[10] CC Uhuegbu, EB Babatunde and CO Oluwafemi. The study of copper zinc sulphide $\left(\mathrm{CuZnS}_{2}\right)$ thin films. Turk. J. Phys. 2008; 32, 39-47.

[11] BH Staurt. Infrared spectroscopy: Fundamental and application. John Wiley \& Sons, New Jersey, 2004.

[12] K Hedayati, A Zndehnam and F Hassanpour. Fabrication and characterization of zinc sulphide nanoparticle and nanocomposites prepared via a simple chemical precipitation method. J. Nonostruct. 2016; 6, 207-12.

[13] B Kavitha, A Ariyapiravi and YY Thangam. Novel method to synthesize and characterize zinc sulfide nanoparticle. Int. J. Appl. Sci. Eng. Res. 2012; 1, 282-6.

[14] OB Ajayi, OK Osuntola, IA Ojo and C Jeyne. Preparation and characterization of MOCVD thin films of cadmium sulphide. Thin Solid Film 1994; 57, 1-6. 
http://wjst.wu.ac.th

[15] IA Ezenwa and NL Okoli. Characterization of chemically synthesized copper zinc sulphide $\left(\mathrm{CuZnS}_{2}\right)$ thin films. Eur. Open Appl. Phys. J. 2015; 1, 1-9.

[16] X Wu, Z Wei, L Zhang, X Wang, H Yang and J Jiang. Optical and magnetic properties of Fe doped $\mathrm{ZnO}$ nanoparticles obtained by hydrothermal synthesis. J. Nanomater. 2014, 2014; 792102.

[17] EE Ezeobele and IA Ezenwa. Optical properties of silver aluminium sulphide ternary thin films deposited by chemical bath method. Int. J. Sci. Tech. 2015; 4, 45-7.

[18] MS Sreejith, DR Deepu, CS Kartha, K Rajeekumar and KP Vijayakumar. Turning the properties of sprayed CuZnS films for fabrication of solar cell. Appl. Phys. Lett. 2014; 105, 202107.

[19] N Kitagawa, S Ito, DC Nguyen and Nishino. Copper zinc sulphur compound solar cells fabrication by spray pyrolysis deposition for solar cells. Nat. Resour. 2013; 4, 142-5.

[20] K Nagamani, MV Reddy, Y Lingappa, KT Ramakrishna Reddy and RW Miles. Physical properties of $\mathrm{Zn}_{\mathrm{x}} \mathrm{Cd}_{\mathrm{i}-\mathrm{X}} \mathrm{S}$ nanocrystalline layers synthesized by solution growth method. Int. J. Optoelectr. Eng. $2012 ; 2,1-4$.

[21] FI Ezema and RU Osuji. Preparation and optical characterization of chemical bath deposited $\mathrm{CdCoS}_{2}$ thin films. J. Appl. Sci. 2006; 6, 1827-32.

[22] J Damisa, B Olofinjana, O Ebomwonyi, F Bakare and SO Azi. Morphological and optical study of thin films of $\mathrm{CuAlS}_{2}$ deposited by metal organic chemical vapour deposition technique. Mater. Res. Express 2017; 4, 1-10.

[23] AO Ansah. 2012, Investigating the optical properties of zinc sulphide thin films deposited from chemical acidic bath. Ph. D. Dissertation. Kwame Nkrumah University of Science and Technology, Kumasi, Ghana. 